\title{
O Modelo do Duplo Quarteto de Linnet
}

\author{
Mário Valente, * Helena Moreira
}

O modelo de estrutura electrónica de valência mais usado a um nivel introdutório é o do octeto de Lewis, mas como modelo simples que é, apresenta bastantes limitações. Em 1960, Linnett propôs um modelo que permite obviar as limitações do modelo de Lewis, conjugando-se muito bem com a noção moderna de domínio electrónico, de Gillespie. Neste artigo pretende-se relembrar este modelo, hoje pouco conhecido, através da apresentação de alguns exemplos pertinentes.

\section{INTRODUÇÃO}

O modelo de distribuição electrónica de valência mais usado ao nível inicial de instrução em química é, indiscutivelmente, o do octeto de Lewis, de 1916. Como modelo simples que é, apresenta algumas limitações, não permitindo, por exemplo, inferir directamente sobre a geometria molecular, nem explicar o paramagnetismo do dioxigénio ou o carácter intermédio da ordem de ligação das ligações no trioxigénio (ozono), ou ainda a diferença entre as energias de dissociação da ligação $\mathrm{C}=\mathrm{O}$ ao passar do dióxido de carbono para as cetonas. É importante notar que este modelo é anterior à descoberta de uma propriedade fundamental dos electrões: o seu spin (1925).

Em 1960 John Wilfried Linnett apresentou um modelo de estrutura electrónica [1-3], baseado no princípio de Pauli, que usou para explicar a geometria de distribuição dos electrões de valência em moléculas, o que Ihe permitiu racionalizar a sua geometria molecular. Esse modelo é baseado, não no octeto de Lewis, mas num duplo quarteto electrónico, em que os electrões de cada quarteto possuem todos um determinado estado de spin ( $\alpha$ ou $\beta$ ).

Linnett reconhece [2] que num octeto de valência se verificam duas correlações electrónicas fundamentais, isto é, duas razões pelas quais a posição de um electrão não é independente da posição de todos os outros electrões, e que são apresentadas em seguida:

Colégio D. Duarte, Rua Visconde de Setúbal, 86, 4200-497 Porto - Portugal madmage1@yahoo.com a) A correlação de carga - devida à repulsão interelectrónica electrostática, que tende a manter todos os electrões o mais afastados possível entre si, e

b) A correlação de spin - que obriga a que um electrão que apresente um dado spin se mantenha o mais afastado possível dos outros electrões com igual spin (sendo, comparativamente, pouco sensível à posição dos electrões de spin diferente).

A correlação de spin aparece como consequência do princípio de Pauli. Segundo Linnett [1,2] (e actualmente, Gillespie [4-6]), a interpretação qualitativa deste princípio aponta para a conclusão de que electrões com o mesmo spin sentem uma repulsão muito acrescida entre si, quando comparada com a que sentem electrões de spins opostos. Assim, quatro electrões de igual spin posicionar-se-ão com maior probabilidade nos vértices de um tetraédro imaginário, centrado no cerne do átomo, já que essa é a disposição geométrica que os mantém o mais afastados entre si, mas equidistantes do núcleo.

A formação de pares electrónicos próximos (de carácter ligante ou não ligante) força, portanto, a que estes sejam compostos por electrões de diferentes spins. De facto, Gillespie lembra [5] que se só se verificasse a correlação de carga não haveria sequer razão para a eventual formação de pares electrónicos próximos.

Num octeto de valência de um átomo isolado, por exemplo o do néon, os dois quartetos de electrões de spins contrários adoptam preferencialmente uma distribuição espacial (Fig. 1) na qual, não só cada electrão está o mais afastado possível dos electrões de igual spin (correlação de spin), como também está afastado dos outros electrões (correlação de carga): os dois tetraedros interpenetram-se.

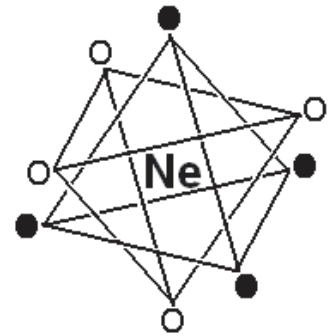

Figura 10 duplo quarteto de valência de Linnett, constituído por quatro electrões de valência de um spin $(\bullet)$ e quatro electrões de valência do outro spin (o), formando dois tetraedros centrados no cerne do átomo de néon

Apresentam-se, de seguida, exemplos de geometrias de distribuição electrónica de valência (GDEV), segundo o modelo de Linnett, para algumas moléculas seleccionadas.

\section{QUATRO HIDROCARBONETOS SIMPLES}

O metano apresenta uma geometria molecular tetraédrica (Fig. 2) devido à disposição dos quartetos electrónicos de valência que coincidem aproximadamente, originando quatro pares electrónicos próximos, de carácter ligante, entre o carbono e os quatro hidrogénios periféricos.

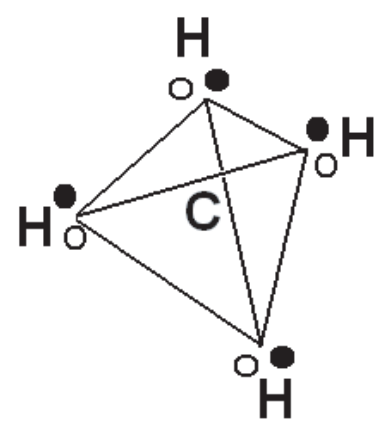

Figura 2 A GDEV para a molécula de metano 
Para o etano a GDEV (Fig. 3) é semeIhante à apresentada para o metano, com a diferença de que um par de electrões de carácter ligante é partiIhado por dois carbonos. Este par ligante permite uma rotação fácil em torno do eixo que passa pelos dois carbonos, possibilitando a adopção de conformações.

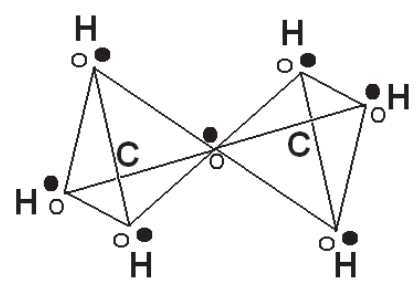

Figura 3 A GDEV para a molécula de etano

No caso do eteno (Fig. 4), há dois pares de electrões de carácter ligante a unir os carbonos e quatro pares de electrões de carácter ligante a unir os quatro hidrogénios aos dois carbonos. Devido aos quatro pares electrónicos ligantes entre os hidrogénios e os carbonos, este composto apresenta uma conformação bastante fixa em torno da ligação carbono - carbono.

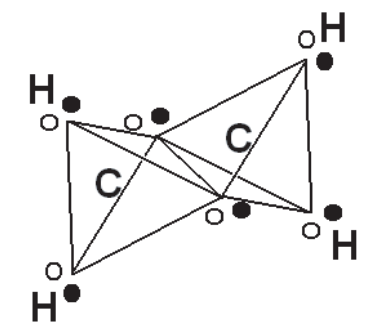

Figura 4 A GDEV para a molécula de eteno

Para o etino (Fig. 5) verifica-se a partilha de seis electrões de carácter ligante entre os carbonos. Neste caso, é de salientar o facto de os dois grupos de três electrões de spins diferentes poderem assumir posições de equilíbrio não coincidentes em pares electrónicos próximos, o que estabiliza a ligação carbono - carbono, na medida em que diminui a repulsão electrostática.

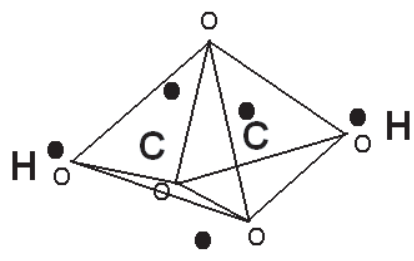

Figura 5 A GDEV para a molécula de etino
Como acima se referiu, estas GDEV estão de acordo com a noção de domínio electrónico de Gillespie [4], na qual o volume (ou espaço) entre os carbonos no etano, no eteno e no etino contém, respectivamente, 2,4 e 6 electrões, correspondendo a uma ligação simples, a uma ligação dupla e a uma ligação tripla.

\section{O DIOXIGÉNIO}

A representação da distribuição electrónica de valência para as moléculas acima referidas usando a notação de Lewis é trivial. No entanto, a aplicação desta notação ao dioxigénio é enganadoramente simples já que não permite explicar o seu paramagnetismo (devido à presença de dois electrões desemparelhados). Esta propriedade do dioxigénio também não pôde ser explicada pela Teoria da Ligação de Valência e a sua racionalização teve de esperar pela Teoria das Orbitais Moleculares, constituindo um dos seus grandes sucessos. Contudo, Linnett [1] apresentou uma alternativa mais simples relativamente à visão da Teoria das Orbitais Moleculares, ao propor a GDEV apresentada na Fig. 6.

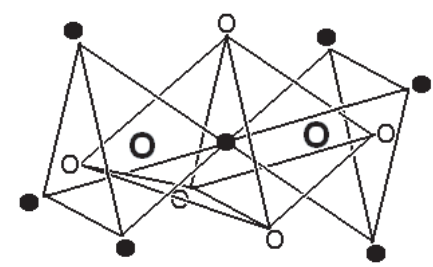

Figura 6 A GDEV para a molécula de dioxigénio

Da contagem dos electrões reconhece-se um desequilíbrio de sete electrões de um spin $(\bullet)$ para cinco electrões do outro spin (o), que explica o paramagnetismo apresentado por esta molécula.

Esta representação para a GDEV do dioxigénio permite reconhecer um domínio electrónico contendo quatro electrões de carácter ligante, que corresponde formalmente a uma ligação dupla.

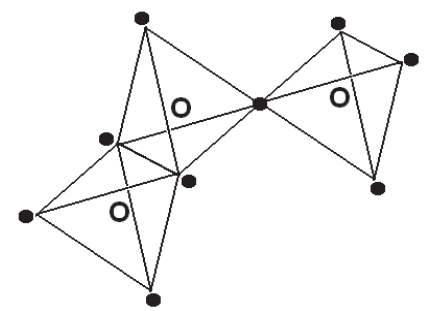

Figura 7 A GDEV para a molécula de trioxigénio. Os dois sistemas de spin estão aqui representados em separado para comodidade de visualização

\section{O TRIOXIGÉNIO (OZONO)}

É usualmente necessário invocar o conceito de ressonância para conseguir a representação do trioxigénio mas Linnett propôs, para esta molécula, a distribuição electrónica de valência apresentada na Fig. 7(abaixo)

Nesta representação encontram-se três electrões de carácter ligante entre cada par de oxigénios, constituíndo dois domínios electrónicos que correspondem formalmente à ordem de ligação intermédia $(1,5)$ que é usualmente associada a esta molécula, sem recurso ao conceito de ressonância.

O oxigénio central apresenta um par próximo de electrões de carácter não ligante, o que confere à molécula a sua geometria angular [7].

\section{A LIGAÇÃO DUPLA CARBONO-OXIGÉNIO}

As energias médias de dissociação apresentam usualmente valores próximos para os mesmos tipos de ligação entre os mesmos átomos. No entanto, a ligação dupla carbono - oxigénio, no dióxido de carbono, apresenta uma energia de dissociação [8] de 804 $\mathrm{kJ} / \mathrm{mol}$, bastante mais elevada que a energia média de dissociação da ligação dupla carbono - oxigénio em cetonas [8], cujo valor é de $729 \mathrm{~kJ} / \mathrm{mol}$.

No dióxido de carbono a GDEV (Fig. 8) envolve a partilha de quatro electrões entre o carbono e cada oxigénio.

O afastamento interelectrónico permitido pela adopção desta GDEV, na qual os dois sistemas de spin são independentes, traduz-se numa estabilização considerável da ligação carbono - oxigénio, pois não há a obrigatoriedade da formação de pares electrónicos próximos.

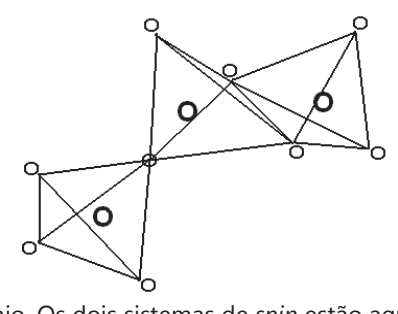
wii 

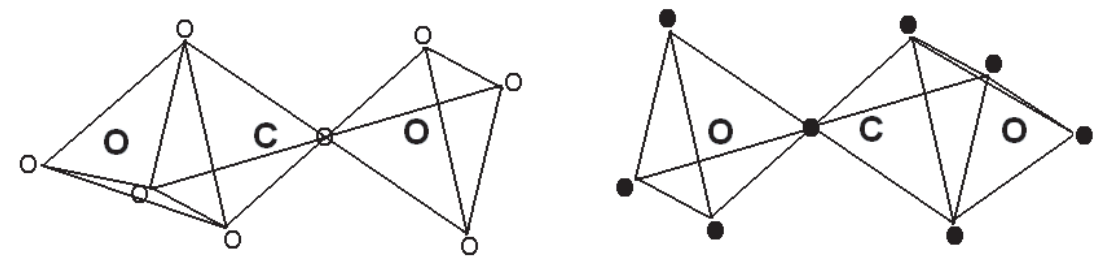

Figura 8 A GDEV para a molécula de dióxido de carbono. Os dois sistemas de spin representam-se em separado para comodidade de visualização

Isto já não é possível no caso da ligação carbono - oxigénio, nas cetonas, na medida em que, para permitir a ligação do carbono do grupo carbonilo a dois outros átomos a correspondente GDEV (Fig. 9) a formação de seis pares próximos de electrões é forçada, com a consequente desestabilização por repulsão electrostática.

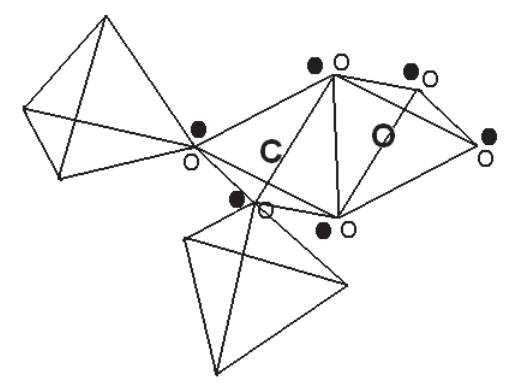

Figura 9 A GDEV para o grupo carbonilo em cetonas

\section{Conclusão}

O modelo do duplo quarteto de Linnett permite explicar de forma muito simples algumas propriedades moleculares como a geometria molecular, o paramagnetismo do dioxigénio, o carácter intermédio da ligação na molécula de trioxigénio e a considerável diferença entre a energia de dissociação da ligação carbono-oxigénio no dióxido de carbono e em cetonas. Consideramos que as ideias de Linnett merecem maior divulgação e destaque na história da ligação química.

\section{RefERÊNCIAS}

[1] M. Green e J.W. Linnett, Journal of the Chemical Society (1960) 4959-4965.
[2] J.W. Linnett, Journal of the Chemical Society (1961) 2643-2653.

[3] W.F. Luder, The Electron-Repulsion Theory of The Chemical Bond, Reinhold, Nova Iorque, 1967.

[4] R.J. Gillespie e E.A. Robinson, Chemical Society Reviews 34 (2005) 396-407.

[5] R.J. Gillespie, J.N. Spencer e R.S. Moog, Journal of Chemical Education 73 (1996) 622-627.

[6] R.J. Gillespie e E.A. Robinson, Angewandte Chemie International Edition in English 35 (1996) 495-514

[7] M. Valente e H. Moreira, Química (Boletim da Sociedade Portuguesa de Química) 102 (2006) 25-27.

[8] R.T. Sanderson, Chemical Bonds and Bond Energy, Academic Press, Nova Iorque, 1971.

\section{Actualidades Científicas}

Progressos NA LUTA contra a DOENÇA DE PARKINSON

A doença de Parkinson é uma doença neurodegenerativa causada por um distúrbio nas vias dopaminérgicas que fazem a ligação entre a substância nigra e o gânglio basal, acompanhada por uma diminuição dos níveis do neurotransmissor dopamina. Esta patologia pode ser medicada com fármacos que conduzam a um aumento dos níveis de dopamina no cérebro. A dopamina não pode ser usada directamente, porque não passa a barreira hemato-encefálica (BHE), recorrendo-se por isso ao uso de precursores. São igualmente utilizados anticolinérgicos, que restabelecem o equilíbrio entre acetilcolina e dopamina, perturbado nesta patologia, e essencialmente ajudam a reduzir o tremor e a rigidez muscular.

Não obstante a existência de uma panóplia de medicamentos que mi- noram os sintomas que acompanham a doença, não existe cura para a doença de Parkinson.

Um artigo publicado em Outubro na Acta Neuropathologica poderá abrir o caminho para novas e mais eficazes terapêuticas para o tratamento de um dos mais comuns e debilitantes distúrbios neurológicos. No artigo «Aggregation of $\alpha$-synuclein by DOPAL, the monoamine oxidase metabolite of dopamine», investigadores da Saint Louis University School of Medicine descrevem a descoberta da substância chave que causa a patologia.

«Pela primeira vez, identificámos o composto que despoleta os eventos no cérebro que causam a desordem. Acreditamos que estas descobertas podem ser utilizadas no desenvolvimento de terapias que de facto parem ou retardem o processo» declarou William J. Burke, o neurologista responsável pelo trabalho.
O composto em questão é um metabolito da dopamina conhecido como DOPAL (3,4- dihidroxifenil acetaldeído) e os cientistas descobriram que é esta molécula a responsável pela agregação da proteina alfa-sinucleína, o que por sua vez provoca a morte dos neurónios dopaminérgicos e leva à doença de Parkinson.

Há muito que se sabe que a alfa-sinucleína - presente na maioria das células do cérebro e cuja função não é inteiramente conhecida, pensando-se que possa estar associada à protecção contra certos tipos de stress - está envolvida na patologia mas não se sabia exactamente o que provocava a aglomeração da proteína. A descoberta de que é o DOPAL que despoleta esta agregação pode levar ao desenvolvimento de terapias neuroprotectoras que evitem a morte dos neurónios dopaminérgicos. 